\title{
The Journal Rises
}

\author{
Atwood D. Gaines
}

Published online: 23 August 2013

(C) Springer Science+Business Media New York 2013

As Editor-in-Chief, I am pleased to apprise Culture, Medicine and Psychiatry's readership of the health of the Journal and its expanding utility for medical social science, especially medical anthropology, and for psychiatry. In 2011 (CMP 34(4)), I reported that our downloads had increased some $300 \%$ since I assumed the editorship of CMP. Building on the solid foundation provided by the earlier editors, (Kleinman, Good, DelVecchio Good, Guarnaccia and Becker), the Internet downloads have now risen some $600 \%$ above baseline (Fall 2007), reaching a rather astonishing 57,000 downloads in 2012. As well, the Journal's Impact Factor (IF) has increased steadily over the last 6 years; it now stands at 1.627 , or double the IF of 6 years ago and $33 \%$ above our 2011 mark of 1.288. The IF for 2010 was 1.250. CMP remains at the top of the social science journals concerned with health and illness but is also ranked 62 of 120 psychiatry journals, thus indicating its relevance in that medical specialty.

The Journal gives thanks to those who labor in-house (Drs Brandy Schillace and Stephanie McClure and recent additions, Ariel Cascio and Catherine Osborn) as well as our reviewers and contributors. The latter group has been growing increasingly large, no doubt in response to the rise of the Journal's visibility. That rise means that CMP will be increasingly selective, offering ever more high quality works for our readership.

In terms of the work of the Journal, we continue the yearlong celebration of Dr. Renée Fox, sociologist/bioethicist extraordinaire. In the last number of the present volume year, the Journal will provide a summary of her research and a listing of key works in the various fields in which she has worked so successfully. Here, we recall that Dr. Fox's first book, Experiment Perilous (1959), reported on her research among cancer researchers and patients in Belgium. It thus foreshadowed the Cultural Studies of Science (and Medicine) now developing as a central component

\footnotetext{
A. D. Gaines $(\bowtie)$

Cleveland, $\mathrm{OH}$, USA

e-mail: atwood.gaines@case.edu
} 
of medical anthropology as well as Cultural Bioethics (Gaines 2011) in its concern for the ethics of research and patient care. Her body of work remains important today.

\section{References}

Fox, Renée

1959 Experiment Perilous: Physicians and Patients Facing the Unknown. Philadelphia, PA: University of Pennsylvania Press.

Gaines, Atwood D

2011 Millennial Medical Anthropology: From There to Here and Beyond or, the Problem of Global Health. Culture, Medicine and Psychiatry 34(1): 83-89. 